\title{
Study of the Conditions for Construction of the Haulage Berm in the Deposit Ledger-Wall
}

\author{
Svetlana Bakhaeva ${ }^{1, *}$, and Elena Chernykh $^{1}$ \\ ${ }^{1}$ T.F. Gorbachev Kuzbass State Technical University, 65000028 Vesennya st., Kemerovo, Russian \\ Federation
}

\begin{abstract}
To reduce transportation distance and shipping cost for rock haulage with a single-side development system, it is relevant to build roads on the spoil bank of the open-pit. The article reviews factors affecting stability of the spoil bank and the most common types of deformation. The backward calculation method for obtaining resistance to shear characteristics of the base rocks in contact with a road embankment has been described. Schemes for road constructions on the spoil bank of the open-pit have been considered. Mining and geometric simulation of the road base has been built. Zoning of the road base as per slope angle of the underlying rock and parameters of the haulage berm allow tracing rapidly axis of the technological and engineering roads for actual engineering and geological conditions. Besides, measures to reduce risk factors of landslides during construction of the haulage berm at deposit ledger-wall have been considered.
\end{abstract}

\section{Introduction}

At single-side development system of the flat mass mineral deposits, deformations of the spoil bank often occur, associated with influence of both natural and man-made factors.

Among the natural negative factors for the deposit ledger-wall, the occurrence of the weak rocks layers in the soil, as well as presence of pressure water in the laminated rocks of the ledger-wall is characteristic.

Negative impact due to the man-made factors is associated with location of the external overburden at the open-pit edge zone above bedrock exposure beneath the burden [1] Atmospheric precipitations accumulate in a dump, after saturation of the dump rock with water at the contact of sediments with the bedrock exposure; water is discharged through the stratification of rocks into the open-pit side. This leads to a gradual decrease in the strength characteristics of the bedrock contacts [2]. The second but not less important factor of the spoil bank disturbing stability is the disparity between the actual bank slope height $\left(h_{a}\right)$ as per bedding of to the recommended $\left(h_{r}\right)$ as per the condition of stability.

The most common types of deformation of the deposit ledger-wall are contact, cover and deep landslides [3].

The cover landslide of weathering products occurs at their strong moistening, and at water saturation of the weathered rocks such landslide converts into a mudslide.

\footnotetext{
* Corresponding author: baxaevas@mail.ru
} 
A distinctive feature of the deep landslides of the laminated rocks of the ledger-wall is a sliding surface, which passes through the stratification of rocks and crosses the layers only at the bottom. In the bottom space there uplifting of rocks.

\section{Materials and Methods}

At existing complexities at excavation of the layers in the ledger-wall often in order to reduce transportation distance and costs for the rock mass haulage there is a need to build internal inter-site roads on the spoil bank of the open pit. Construction of the roads is economically advantageous by carrying out construction of an embankment using rock above the soil of the extracted layer.

However, due to the great incidence angle of the coal floor, moistening of the base, or presence of weak underlying soil rocks, it is not possible to provide the width of the road necessary for the passage of the technological transport.

Upon reaching a certain height, the embankment slides completely or partially along the slope surface (Fig. 1). It happens when incidence angle of the soil layer is greater than angle of internal friction of the 'base to embankment' contact. The fact of the rock sliding is an indicator for the discrepancy between the bearing capacity of the base and the weight of the filled rocks. Herewith, often to restore the embankment and provide the necessary width of the road, an additional volume of overburden is imported, which leads to larger-scale consequences of the landslide.

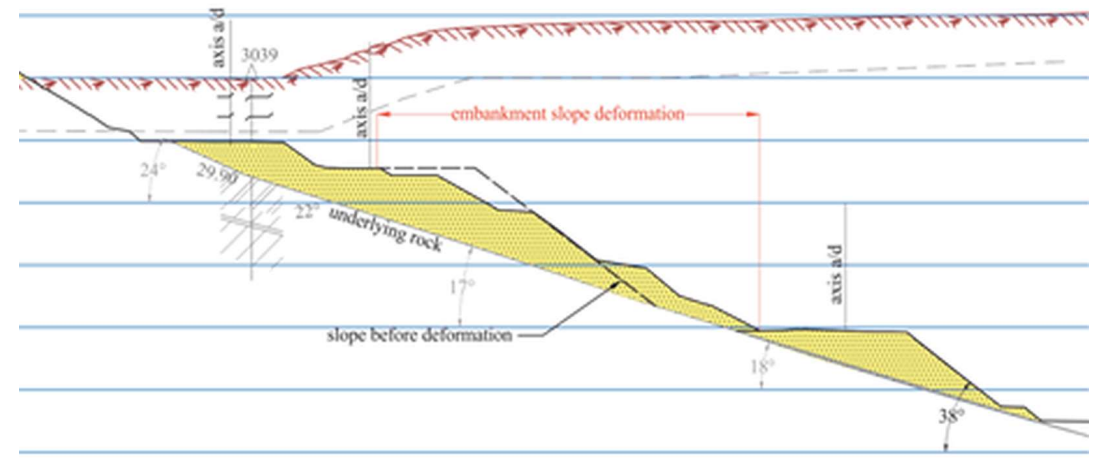

Fig. 1. Embankment slide along slope.

In this case, when there was a landslide of the road embankment, it is necessary to determine rock strength characteristics on the embankment to the base contact by the backward calculations for the true conditions method using set of equations:

$$
\sum_{1} T_{i} \geq f \sum_{1} N_{i}+C \sum l_{i}
$$

where $T_{i}$ - tangent component of individual block weight, $\mathrm{t} ; f-$ internal friction coefficient; $N_{i}$ - normal component of individual block weight, $\mathrm{T} ; C$ - soil coupling, $\mathrm{kg} / \mathrm{sm}^{2} ; l_{i}$ - probable slide surface length, $\mathrm{m}$.

After rock landslide, when adhesion forces on the sliding surface cease to operate, the equilibrium of the collapsed masses happens when shear forces are balanced by friction forces only, i.e. the equation is in force:

$$
\sum_{2} T_{i} \leq f \sum_{2} N_{i}
$$

From the joint solution of the two equations hereinabove they determine angle of internal friction on contact $\varphi^{\prime}$ (the most significant indicator of the embankment stability) 
and coupling $\mathrm{C}^{\prime}$.

According to the characteristics of the shear resistance of the base rocks obtained by backward calculation, they compute the embankment permissible height taking into account additional load from a loaded dump truck.

Calculation of the embankment height in this case is performed similarly to the filled layer of the dump [3], replacing dump truck specific load with the weight of the equivalent rock layer $\Delta \mathrm{H}$.

$$
\Delta \mathrm{H}=\frac{\mathrm{P}}{b \cdot \gamma}
$$

where $\mathrm{P}$ - loaded dump truck weight, $\mathrm{t} ; \gamma-$ soil density $\mathrm{t} / \mathrm{m}^{3}, \mathrm{~m} ; b-$ dump truck floor space, $\mathrm{m}$.

\section{Results and Discussion}

Should the width permissible as per the road stability condition does not meet the dimensions corresponding to the road category, according to the Code of rules Industrial Transport, the road should be formed according to the scheme 'cut-and-fill' (Fig. 4). In this case, the required width of the road is provided due to partial cutting of the underlying soil rocks - cutting of the haulage berm along deposit ledger-wall.

At this point it is necessary to stipulate that cutting of the haulage berm is allowed only in the hard thick underlying rock, for example in sandstones. The limiting condition is the permissible height of rock cutting, which at incidence angles of the underlying bedrock is greater than angle of internal friction on the contact layers and is determined by the expression $[4,5,6]$.

$$
h=\frac{C_{n}^{\prime} \cos \varphi_{n}^{\prime}}{\rho \cos \beta \sin \left(\beta-\varphi_{n}^{\prime}\right)^{\prime}}
$$

where $C_{n}^{\prime}, \varphi_{n}^{\prime}$ - estimated values of coupling $\left(\mathrm{t} / \mathrm{m}^{2}\right)$ and angle of internal friction (degree) contact, respectively; $\rho$ - rock density, $\mathrm{T} / \mathrm{M}^{3} ; \beta$ - bed slope angle, degree.

The defining indicator of the cutting height of the layers (Formula 4), as well as the height of the stable road embankment is angle of internal friction on contact; at its changing on $2^{\circ}$ only the cutting height decreases on $5 \mathrm{~m}$ (Fig. 2).

Should the undercutting solid is composed of rock layers of different strength characteristics of contacts, to prevent sliding of the cut off layers of the underlying thickness of rocks, the height of the cut is determined by the weakest one of them.

Let's consider influence of incidence angle of the base on the parameters of the road at construction of the embankment on solid foundation for actual engineering and geological conditions $[7,8]$. Strength characteristics of the 'embankment - underlying rock' contact: adhesion $-1.5 \mathrm{t} / \mathrm{m}^{2}$; internal friction angle $-17^{\circ}$. Specific load of dump truck $-7.3 \mathrm{t} / \mathrm{m}^{2}$. 


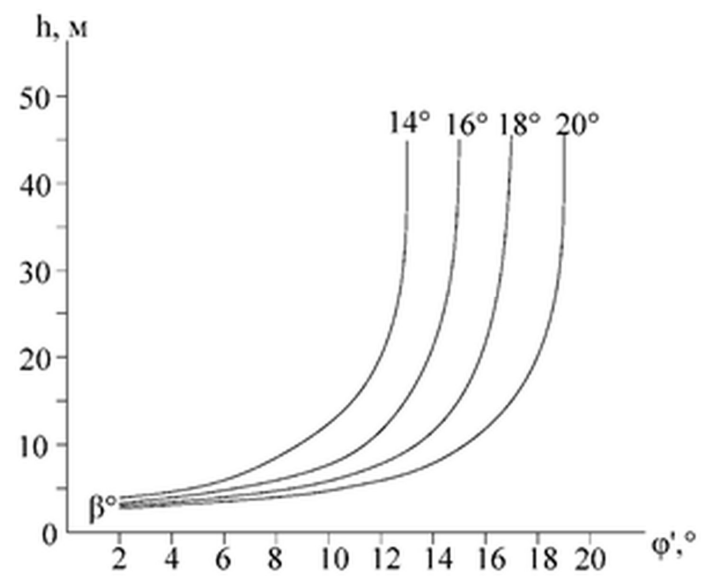

Fig. 2. Dependence graph of the permissible undercut height to angle of internal friction on contact.

Calculations have determined that stability embankment of a two-lane road (up to $30 \mathrm{~m}$ wide) is provided at the base incidence angle up to $18^{\circ}$ (Fig. 3,a), single road - up to $22^{\circ}$ (Fig. 3,b and 6,c). From the above example, it is clear that increasing incidence angle of the base on $4^{\circ}$, the embankment height should be reduced on $1.5 \mathrm{~m}$ that will reduce the width of the road from 30 to $19 \mathrm{~m}$.

Forming the road embankment on contact with weak rocks for passage of a dump truck with greater specific load, influence of incidence angle of the base is even more significant, which can be demonstrated by the following example.

Strength characteristics of the contract 'embankment to underlying rock': adhesion 1 $\mathrm{t} / \mathrm{m}^{2}$; internal friction angle $-9^{\circ}$. Specific load of dump truck $10 \mathrm{t} / \mathrm{m}^{2}$.

The embankment stability is not provided at incidence angle of the base from $16^{\circ}$. The road-bed can only be constructed as per 'cut-and-fill' scheme; furthermore a greater part of road-bed is located in the cut part of the haulage berm.
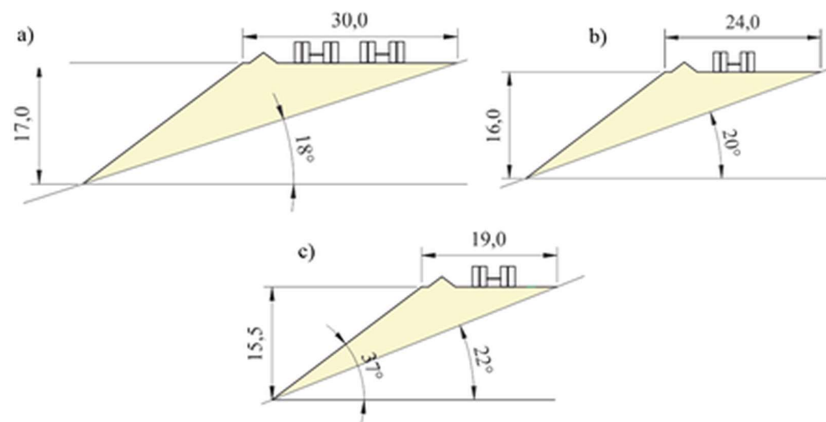

Fig.3. Parameters of the road formation on sloping solid ground.

A two-lane road with the total width of $32.5 \mathrm{~m}$ (along the embankment up to $15.5 \mathrm{~m}$ ) is acceptable to form at the base incidence angles of less than $16^{\circ}$ (Fig. 4, a). At the base angle of $18^{\circ}$, it is possible to build a single-lane road with the total width of $24 \mathrm{~m}(11.5 \mathrm{~m}$ along the embankment), at $20^{\circ}$ - a single-lane road in cramped conditions with the embankment width of only $9 \mathrm{~m}$ (Fig. 4,b and 4,c). 

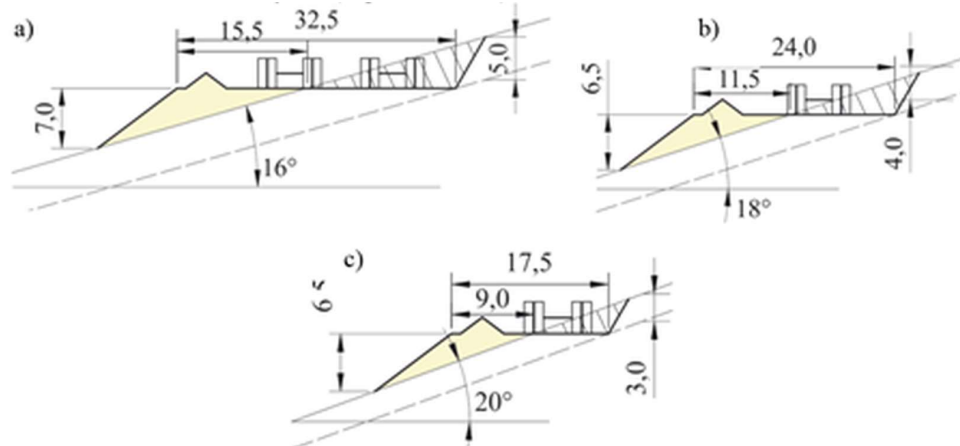

Fig.4. Parameters of the road formation on sloping weak ground.

The given example confirms a significant influence of incidence angle of the base on parameters of the road, which provides safe conditions for cargo transportation.

Analysis of the available mining and graphic documentation for twenty-three open-pits has determined that at incidence angles of the base less than $14^{\circ}$, the embankment stability for the road is usually provided. At steeper incidence angles there are different in scale deformation of the embankment. In this regard, there is a need to create a mining and geometric model of the dimensional field of placement of slope angle of the underlying rock.

Mining and geometrical model is depicted as isolines of topographical function of slope angle of the underlying rock. The designated topographical function actually does not exist in nature; it is derived from the surface soil deposits and is built by indirect method as per the marks of the underlying rock, measured in wells by the AutoCAD Civil software (Fig. $5)$.

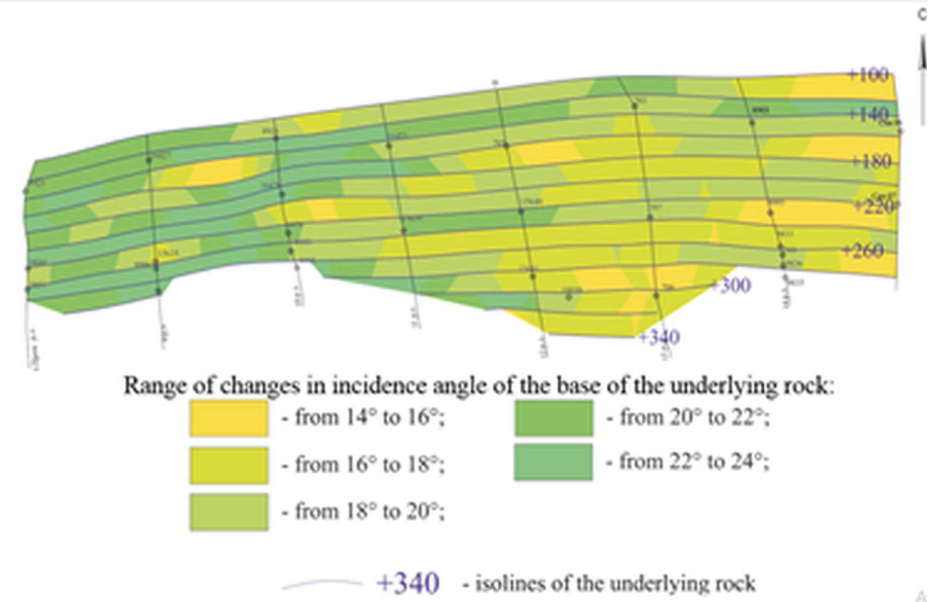

Fig.5. Zoning of the road base as per slope angle.

The cross-sectional height of the isolines is commensurate with the random component inherent in the placement at this stage of exploration and satisfies the inequality $h \geq t_{p} \sigma_{\text {сл }}$, where $\sigma_{\text {сл }}$ - evaluation of the random component of the indicator placement; $t_{p}$ - quantile of the errors distribution law for indicator determination, $t_{p}=1.5$.

For the topographical surface 'deposit form' a model of the inhomogeneous random field is more suitable, and in this case the estimation of the random component of the indicator placement is performed by the formula: 


$$
10 \geq 1,5 \cdot 2,64
$$

where $\Delta_{\mathrm{i}}^{\prime \prime}$ - second differences of indicators in the measurement points of the indicator $i$ and $(i+1) ; n$ - number of measurement points.

The most favorable areas, from the stability for the construction of technological roads point of view, in deposit ledger-wall (slope angle of the underlying rock is less than $14^{\circ}$ ), are highlighted by a single color, the other areas are painted in a specific color for the entire range of variation of slope angle of the underlying rock in a distance equal to the step of the isoslopes construction, for example, $h=2^{\underline{0}}$.

The obtained plan, which reflects the zoning on slope angle of the underlying rock, will allow to quickly trace the axes of technological roads and by the estimated parameters to construct roads for actual engineering and geological conditions $[9,10,11]$.

\section{Conclusions}

Reducing risk of the hazardous engineering and geological phenomena (landslides) is provided by accomplishing of measures to reduce negative impact of risk factors (Table 1) [12-15].

Table 1. Measures to reduce risk factors of landslides at formation of haulage berm in deposit ledge-wall.

\begin{tabular}{|c|c|c|}
\hline No & Risk factors & Measures to reduce risk factors \\
\hline 1 & $\begin{array}{l}\text { Strength characteristics of the } \\
\text { embankment rocks }\end{array}$ & Form embankment of nitrogen-swell rocks \\
\hline 2 & $\begin{array}{l}\text { Strength characteristics of contact } \\
\text { rocks of the embankment with the } \\
\text { base }\end{array}$ & $\begin{array}{c}\text { Protect soil from residual coal and carbonaceous rocks } \\
\text { by excavator or tractor ripper to a solid base without } \\
\text { drilling and blasting }\end{array}$ \\
\hline 3 & $\begin{array}{l}\text { Incidence angle of the } \\
\text { embankment base }\end{array}$ & Perform zoning of the base on incidence angle \\
\hline 4 & $\begin{array}{l}\text { Technology for embankment } \\
\text { construction }\end{array}$ & $\begin{array}{c}\text { Form embankment by small (up to } 1 \mathrm{~m} \text { ) layers with } \\
\text { thorough compaction }\end{array}$ \\
\hline 5 & $\begin{array}{c}\text { Static and dynamic loads from } \\
\text { vehicles }\end{array}$ & $\begin{array}{l}\text { Perform calculation of the embankment stability taking } \\
\text { into account dump truck with maximum specific load }\end{array}$ \\
\hline 6 & $\begin{array}{l}\text { Hydration of the embankment } \\
\text { rocks on contact with the base }\end{array}$ & $\begin{array}{l}\text { Provide drainage and removal of rain, melt and } \\
\text { ground waters, leaking from the upper ledges and } \\
\text { accumulating on the sites }\end{array}$ \\
\hline
\end{tabular}

\section{References}

1. J. Read, P. Stacey, Guidelines for open pit slope design (Sptinger, New York, 2010)

2. M. Ahmad, R.K. Umrao, M.K. Ansari, R. Singh, Geomaterials, 15, 2 (2013)

3. B. Buragohain, J. Kundu, K. Sarkar, T.N. Singh, Int. J. Earth Sci. Eng., 269, 50 (2016)

4. R. Anbalagan, B. Singh, D. Chakraborty, A. Kohli, A field manual for landslide investigations (DST, Bombay, 2007)

5. R. D. Espinoza, P. C. Repetto, B. Muhunthan, General framework for stability analysis of slopes (Geotechnique, Lion, 1992)

6. S. Bakhaeva, D Guriev, Proceedings of the 8th Russian-Chinese Symposium, 188, 55 (2016) 
7. S. Bakhaeva T Mikhaylova., D. Guriev, Geotech. Eng., 5, 21 (2016)

8. J. Kundu, K. Sarkar, A. Singh, Integrating structural and numerical solutions for road cut slope stability analysis - a case study (Taylor \& Francis Group, London, 2016)

9. J. Kundu, K. Sarkar, A. Tripathy, T. Singh., J. Earth Sys. Sci., 126, 100 (2017)

10. L. M. Highland, P. Bobrowsky, The landslide handbook-a guide to understanding landslides (Geology, Ostin, 2008)

11. O. Hungr, S. Leroueil, L. Picarelli, Landslides, 16, 7 (2014)

12. D. Cruden, Bul. Int. Eng. Geol., 27, 9 (1991)

13. E.M. Dawson, W.H. Roth, A. Drescher, Geotechnical, 35, 20 (1999)

14. J.M. Duncan, J. Geotech. Eng., 55, 23 (1996)

15. D. Loukidis, P. Bandini, R. Salgado, Geotechnical, 46, 3 (2003) 